Revue d'histoire de l'Amérique française

DAV REVUE D.HISTOIRE DE L'AMÉRIQUE FRANÇAISE

\title{
Implantation et expansion de l'Union internationale des travailleurs en chaussures au Québec de 1900 à 1940
}

\section{Jacques Rouillard}

Volume 36, numéro 1, juin 1982

URI : https://id.erudit.org/iderudit/304032ar

DOI : https://doi.org/10.7202/304032ar

Aller au sommaire du numéro

Éditeur(s)

Institut d'histoire de l'Amérique française

ISSN

0035-2357 (imprimé)

1492-1383 (numérique)

Découvrir la revue

Citer cet article

Rouillard, J. (1982). Implantation et expansion de l'Union internationale des travailleurs en chaussures au Québec de 1900 à 1940. Revue d'histoire de l'Amérique française, 36(1), 75-105. https://doi.org/10.7202/304032ar d'utilisation que vous pouvez consulter en ligne. 


\title{
IMPLANTATION ET EXPANSION DE L'UNION INTERNATIONALE DES TRAVAILLEURS EN CHAUSSURES AU QUÉBEC DE 1900 À 1940*
}

\author{
JACQUES ROUILLARD \\ Département d'histoire \\ Université de Montréal
}

Parce que le syndicalisme national et catholique est né et a grandi au Québec, on peut être porté à identifier l'histoire du syndicalisme québécois à ce seul mouvement. Et pourtant, la CTCCCSN n'a jamais regroupé la majorité des syndiqués québécois et elle n'a jamais constitué non plus le principal groupe syndical au Québec. Comme dans l'ensemble de l'Amérique du Nord, ce sont les syndicats affiliés aux fédérations internationales (étatsuniennes) qui ont possédé les effectifs les plus nombreux dans la province. Depuis leur fondation au début du siècle, les syndicats catholiques n'ont regroupé qu'environ 25 à $30 \%$ des syndiqués québécois, alors que les "internationaux» en réunissaient de 45 à $70 \%$ selon les périodes. Le syndicalisme international peut donc se réclamer d'un enracinement au Québec aussi profond que la CTCC-CSN.

Malgré son importance, peu d'études lui ont été consacrées comparativement aux organisations catholiques. Depuis toujours, les intellectuels ont eu tendance à dénigrer les «internationaux», perçus comme un «corps étranger», et à leur préférer la CTCCCSN, présentée comme un mouvement authentiquement québécois. Pourtant, les «internationaux» se sont implantés dans la province bien avant les syndicats catholiques, qui eux aussi ont été soumis à de fortes influences extérieures. L'idéologie qui a inspiré le syndicalisme catholique a été empruntée aux catholiques sociaux d'Europe tout comme les «internationaux» sont redevables de leur conception de l'action syndicale à nos voisins du Sud. Guy Rocher fait souvent remarquer que les milieux intellectuels québécois, plus proches de la France, ont eu tendance à ignorer la forte influence

\footnotetext{
* Ce texte est le fruit d'une recherche subventionnée par le Ministère de l'Éducation (F.C.A.C.) sur la main-d'oeuvre manufacturière du textile et de la chaussure au Québec et aux États-Unis (1900-1940). Je remercie M. Michel Brunet du département d'histoire de l'Université de Montréal pour ses commentaires sur ce texte, de même que Denyse Baillargeon et Marcel Leduc pour l'aide apportée à compléter cette recherche.
} 
étatsunienne au Québec ${ }^{1}$. Il me semble que cette observation vaut dans le cas du syndicalisme car, encore aujourd'hui, malgré leur importance numérique, les «internationaux» sont peu étudiés et ont mauvaise réputation, à la fois à cause de leur idéologie et de leur affiliation étrangère.

C'est aussi pour ces deux raisons qu'au début du siècle, ils encouraient la réprobation des journaux, du clergé et des élites politiques. Et pourtant, en s'appuyant uniquement sur le milieu ouvrier, les syndicats internationaux ont recruté massivement des syndiqués au Québec. Jusqu'à tout récemment, la presque totalité du leadership international émanait de travailleurs on ne peut plus authentiques. Expliquer la présence internationale au Québec par le seul jeu de la domination étatsunienne ne résiste pas à l'analyse. C'est parce qu'ils ont obtenu le support actif de milliers de travailleurs québécois que les syndicats internationaux ont pu s'établir et progresser dans l'adversité.

Il ne faudrait pas croire non plus que les «internationaux» recrutaient en majorité des travailleurs anglophones. Bien qu'il soit difficile de trouver des données précises à ce sujet, un observateur attentif de la scène syndicale, Alfred Charpentier, estimait en 1918 que les deux tiers (68\%) des syndiqués internationaux à Montréal étaient francophones ${ }^{2}$. Comme il y avait aussi beaucoup de syndicats internationaux à l'extérieur de la métropole, le pourcentage de francophones dans leurs rangs à l'échelle du Québec devrait être supérieur à l'estimation de Charpentier pour Montréal. Personnellement, nous estimons au plus à $25 \%$ les nonfrancophones parmi les syndiqués internationaux au Québec depuis 1910. N'oublions pas qu'on retrouvait la majorité des syndiqués internationaux dans la construction et les chemins de fer, où les francophones constituaient la grande majorité de la main-d'oeuvre. On aurait donc tort d'identifier les «internationaux» aux anglophones et la CTCC aux francophones.

Quoique nous nous étonnions que ce fait n'ait pas été relevé plus tôt, les «internationaux» ont été un rempart des libertés individuelles et un lieu d'apprentissage de la démocratie au Québec. Comme nous l'avons montré ailleurs ${ }^{3}$, ils ont contribué à diffuser les valeurs libérales au Québec quand ces valeurs subissaient les assauts répétés du clergé et, plus tard, du gouvernement Duplessis. Depuis sa fondation en 1916, leur organe au Québec, Le Monde

\footnotetext{
Guy Rocher, Le Québec en mutation (Montréal, Hurtubise HMH, 1973), 89-108.

2 Compte rendu d'une journée sociale à la Villa Saint-Martin (avril 1918), 15. Archives de l'Ecole Sociale populaire, Dossier syndicalisme.

Jacques Rouillard, Les Syndicats nationaux au Québec de 1900 à 1930 (Québec, PUL, 1979), 252-257.
} 
ouvrier, s'est fait le défenseur de ces valeurs contre la presse cléricale. Parmi les raisons qui ont incité les «internationaux» à fonder la fédération provinciale du travail du Québec (FPTQ) en 1937, figure en bonne place leur désir de faire échec au corporatisme et au fascisme dans la province ${ }^{4}$. Plus récemment, la FTQ décidait, à son congrès de 1979 , de formuler les principes de base de son projet de société. Quoiqu'ils aient qualifié ce projet de socialdémocrate, les délégués au congrès entérinaient, sans s'en rendre compte, des objectifs que poursuivaient leurs prédécesseurs depuis le début du siècle. Les principes adoptés comme le soutien aux institutions démocratiques, la nationalisation de certains moyens de production, l'accès égalitaire aux mesures sociales, la syndicalisation libre et l'égalité pour les femmes ont constitué en substance des revendications du mouvement syndical international depuis son origine ${ }^{5}$.

L'étude des syndicats internationaux est difficile à cause des structures très décentralisées du mouvement qui séparent les institutions à caractère politique des organisations professionnelles, et qui divisent les travailleurs selon leur métier ou l'industrie où ils travaillent. Cette difficulté se double du problème de l'affiliation des syndicats à une fédération professionnelle ou industrielle ayant son siège social aux États-Unis. Un syndicat international à Montréal a davantage de liens avec sa fédération qu'il ne peut en avoir avec les autres syndicats internationaux de la métropole. Dans ces conditions, il faut d'abord faire porter sa recherche sur les syndicats appartenant à la même fédération professionnelle.

C'est ce que nous avons entrepris de faire pour une de ces fédérations, l'Union internationale des travailleurs en chaussures (UITC). Ce n'est pas qu'elle ait compté les effectifs les plus nombreux au Québec, mais elle a été au centre de plusieurs conflits intersyndicaux et nous avons eu la chance de consulter les archives de la fédération à Boston. Cet article sur l'implantation et l'expansion de l'UITC constitue le premier volet de notre étude; un second tracera le bilan de l'action du syndicat au Québec.

\section{Implantation de l'Union internationale}

Ce n'est qu'en 1900 que l'Union internationale s'intéressera à regrouper en son sein les travailleurs canadiens. Son viceprésident, Collis Lovely, vint à Montréal dans ce but en août 1900 . L'industrie de la chaussure employait alors un nombre imposant de travailleurs au Québec, près de 10000 en 1901, oeuvrant dans

$4 \quad$ Le Monde Ouvrier, 7 août 1937, 4.

5 FTQ, Procès-verbal du congrès, 26-30 novembre 1979, 8-22. 
114 manufactures et assez également répartis entre Montréal et Québec ${ }^{6}$. La fédération qui ne comptait que 10618 membres aux Etats-Unis, espérait en recruter 6000 au Québec ${ }^{7}$.

Mais le travail de syndicalisation allait s'avérer particulièrement difficile, pour deux raisons: d'abord, parce que les travailleurs de la chaussure avaient déjà des syndicats à Montréal, Québec, Saint-Hyacinthe et Trois-Rivières; ensuite parce que la barrière de la langue accentuait le caractère étranger de la fédération. À la fin du siècle, les travailleurs de la chaussure de Montréal et de Québec quittèrent graduellement les assemblées des Chevaliers du travail pour fonder des syndicats de métier parmi les monteurs, les tailleurs et les cordonniers-machinistes. Peu de temps après, des liens se tissèrent entre syndicats de villes différentes pour donner naissance à des fédérations de métier totalement québécoises.

En 1898, le syndicat des monteurs de Montréal s'unissait à celui de Saint-Hyacinthe et de Québec pour fonder l'Union protectrice des cordonniers-monteurs du Canada ${ }^{8}$. Leur geste fut suivi l'année suivante par les cordonniers-machinistes qui mirent sur pied la Fraternité des cordonniers unis de la Puissance du Cana$\mathrm{da}^{9}$. Ces deux fédérations, qui pouvaient compter environ 1000 membres chacune, organisaient des congrès annuels: elles avaient constitué un fonds de grève et se consultaient sur les augmentations de salaire à exiger des manufacturiers ${ }^{10}$. Ce n'était donc pas des travailleurs isolés que l'Union internationale venait syndiquer au Québec: elle faisait face à de vigoureuses organisations syndicales. Aussi pour éviter les douloureux conflits qu'était susceptible d'engendrer la création de syndicats parallèles, les organisateurs internationaux s'employèrent à convaincre les syndicats existants de passer en bloc à l'Union internationale.

En 1901, le président de l'Union internationale, John F. Tobin, vint personnellement au Québec à plusieurs reprises pour persuader les travailleurs de la chaussure de se joindre à sa fédération. Accompagné de dirigeants syndicaux locaux appartenant à des fédérations internationales, il prononça plusieurs discours à Montréal, à Québec et à Saint-Hyacinthe, vantant les mérites de son organisation. Au retour de son premier voyage en terre québécoise, il écrivait:

\footnotetext{
Canada, Recensement du Canada (1901), III: 32-33.

The Shoe Workers' Journal, février 1901, 1; février 1904, 20.

La Presse, 9 décembre 1898, 9.

Canada, Ministère du Travail, La Gazette du travail, déc. 1901, 382; La Presse, 30 mars 1898,8 .

10 Le Soleil, 1 septembre 1900, 5; 28 août 1901, 1; J. Rouillard, op. cit., 23-24.
} 
While this experience in organizing is a new one, it is valuable in the fact that there is noticeable difference between the French and English in dealing with important questions. They move "en bloc», as they say. They take more pains in reaching a conclusion, and once having determined upon their course, all move at once. I have been obliged to reverse a preconceived opinion that the French acted upon impulse. ${ }^{11}$

Les Canadiens français étaient si peu impulsifs que Tobin s'impatienta de la lenteur des syndicats à prendre une décision. L'Union des tailleurs de cuir et celle des cordonniers en «turns» de Montréal avaient joint la fédération au début de 1901, mais les cordonniersmonteurs de la métropole et les syndicats de Québec et de SaintHyacinthe se faisaient tirer l'oreille ${ }^{12}$.

Ayant eux-mêmes mis sur pied des fédérations de métier, ils étaient réticents à les dissoudre pour se fondre dans une organisation étrangère. Les adversaires de l'affiliation invoquaient que c'était manquer de patriotisme que de sacrifier l'autonomie des syndicats canadiens ${ }^{13}$. Le caractère anglais de la fédération compliquait davantage la situation car ses chefs ne pouvaient prendre publiquement la parole en français. Tobin s'en rendait parfaitement compte et écrivait dans son rapport à l'exécutif en 1901:

There is one very great drawback in our work in the Province of Québec, which is the fact that the shoe workers, with very few exceptions, speak and understand only the French language, and all our work, so far, has to be done through an interpreter. ${ }^{14}$

Pour donner un visage plus français à la fédération, la constitution fut traduite et quelques pages en français ajoutées au journal de la fédération. On prit soin également au siège social de répondre en français à la correspondance adressée en français. Ces efforts parvinrent sans doute à redonner une meilleure image à la fédération au Québec.

Mais les travailleurs étaient toujours hésitants. Aux facteurs énumérés plus haut, s'ajoutent d'autres raisons qui expliquent leurs réserves. La cotisation élevée de l'Union internationale, 25 sous par semaine, pouvait en rebuter plusieurs ${ }^{15}$. Il n'y a pas de

11 The Shoe Workers' Journal, février 1901, 13.

12 La Presse, 29 janvier 1901, 3; 31 janvier 1901, 7; 10 octobre 1901, 6; Lettre de J. Tobin à S. Gompers, 22 octobre 1901, Archives de la FAT, National Unions Files, bobine 2 .

13 La Presse, 24 juillet 1903, 9.

14 Rapport de J. Tobin au Comité exécutif, 27 février 1901, Archives de la Boot and Shoe Workers' Union, General Executive Board, Actions and Decisions.

15 La Presse, 7 février 1901, 9; The Shoe Workers' Journal, août 1902, 21. 
doute non plus que les déclarations des manufacturiers de ne jamais négocier avec cette fédération ont influé sur la décision des travailleurs ${ }^{16}$. De même, à Québec, la suspicion du clergé catholique envers la fédération a sûrement aidé à tenir les internationaux à l'écart de la ville.

Peu avant la venue de Tobin à Québec en février 1901, Mgr Bégin, avait été mêlé à titre d'arbitre au règlement d'un long conflit dans l'industrie de la chaussure. Selon son jugement les constitutions des trois syndicats de la chaussure de Québec devaient subir des modifications, parce qu'elles portaient «de fortes atteintes à la liberté personnelle, à la liberté de conscience et à la justice» ${ }^{17}$. Les autorités ecclésiastiques réclamaient en fait de soumettre à leur approbation la constitution des syndicats de la chaussure. Si un de ces syndicats avait manifesté l'intention de s'affilier à l'Union internationale, l'archevêque aurait sans doute refusé la nouvelle constitution. Les ouvriers de Québec le savaient; le président Tobin l'avait compris à son retour de Québec:

This Union recognized the good offices of clergymen in attempting to restore peace between employer and employed, but on matters of organization and matters pertaining to the constitution a line must be drawn. ${ }^{18}$

L'article contestait au clergé le droit d'intervenir dans le fonctionnement interne des syndicats. Mais l'Union internationale ne tenta pas d'autres efforts pour persuader les syndicats québécois; elle avait déjà assez à faire avec ceux de Montréal.

Dans la métropole, le plus important syndicat de la chaussure, l'Union des monteurs, tardait à prendre une décision à propos de son affiliation internationale. Impatient d'implanter solidement sa fédération à Montréal, le président Tobin commit un impair malheureux, en septembre 1901, lorsqu'il conclut une entente avec la compagnie de chaussures Ames-Holden lui permettant d'apposer sur ses chaussures la marque de fabrication syndicale internationale ${ }^{19}$. En échange de cette étiquette, la compagnie s'engageait à n'employer que des travailleurs appartenant à l'Union internationale. Le geste était d'autant plus odieux que les travailleurs de cette firme, qui faisaient partie de l'Union des monteurs, étaient en grève depuis six mois. En signant cette entente, l'Union internationale s'engageait à fournir à l'entreprise tous les travailleurs dont

16 La Presse, 4 février 1901, 2; 14 juin 1901, 12.

17 Sentence arbitrale de Mgr Bégin, archevêque de Québec, 10 janvier 1901, La Semaine religieuse, 26 janvier 1901, 357.

18 The Shoe Workers' Journal, novembre 1901, 13.

19 La Presse, 10 octobre 1901, 6; 17 septembre 1901, 2; 18 septembre 1901, 8. 
elle pourrait avoir besoin, même des briseurs de grève. Peut-être Tobin espérait-il forcer la main de l'Union des monteurs? Quoi qu'il en soit, son geste eut la conséquence contraire puisque l'Union des monteurs l'interpréta comme une déclaration de guerre.

Non seulement les monteurs rejetèrent-ils l'offre d'affiliation, mais ils mirent sur pied en novembre la Fédération canadienne des cordonniers (FCC) qui se proposait d'organiser l'ensemble des travailleurs de la chaussure ${ }^{20}$. La maladresse du président Tobin avait eu pour conséquence la création d'une fédération concurrente qui allait lui disputer l'adhésion des travailleurs. Ainsi, peu après, la FCC formait à Montréal un syndicat de machinistes et de tailleurs et elle émettait sa propre marque de fabrication syndicale ${ }^{21}$. Elle réussit même à conclure une entente avec l'Association des manufacturiers de chaussures de Montréal en vue de régler à l'amiable les conflits qui surviendraient dans leurs ateliers ${ }^{22}$. La plupart des manufacturiers manifestaient une nette préférence, du moins en 1901 et 1902, pour transiger avec la Fédération canadienne ${ }^{23}$.

Inquiet de ces développements, Tobin conçut le projet de discréditer la FCC en l'isolant du mouvement syndical canadien. Grâce aux bons offices de Gompers, il obtint l'exclusion de l'Union des monteurs du Conseil des métiers fédérés de Montréal, organisme qui regroupait surtout des syndicats internationaux. Geste qui allait avoir des conséquences graves pour l'avenir du mouvement syndical canadien, il résolut également de faire tout en son pouvoir pour exclure la FCC du Congrès des métiers et du travail du Canada (CMTC).

Peu avant le congrès annuel du CMTC, il envoya dans ce but une lettre circulaire aux syndicats internationaux au Canada pour qu'ils votent l'exclusion de la FCC. Après un bref historique de ses démêlés avec la FCC, il concluait:

Nous émettons cette circulaire pour exciter [sic] toutes et chacune des unions locales internationales du Canada de devenir affiliées au Congrès Canadien des Métiers et du Travail, et d'envoyer une pleine délégation à la convention qui sera tenue à Berlin, Ont., au mois de septembre prochain, afin que le

20 Ibid., 5 novembre 1901, 8 .

21 Ibid., 4 décembre 1901, 2; 30 octobre 1902, 9.

22 Lettre de J. Tobin au Comité exécutif, 28 décembre 1901, Archives de la BSWU, General Executive Board, Actions and Decisions; lettre de J. Hagar, président de l'Association des manufacturiers à W.L. Mackenzie King, 6 novembre 1902, Canada, Ministère du Travail, Dossier chaussure, 1902-1903. L'archevêque de Montréal, Mgr Bruchési, avait approuvé ce règlement qui ressemblait dans ses grandes lignes à celui de Québec.

23 Lettre de M. Tétreault à la Presse, 22 mai 1902, La Presse, 31 mai 1902, 2. 
Congrès soit en position de se prononcer, soit pour une seule organisation dans un métier ou bien se prononcer au contraire. (...) Nos unions locales au Canada seront représentées, et essayeront à [sic] soutenir le principe d'une seule union dans un métier. ${ }^{24}$

À l'appui de sa thèse, Tobin invoquait un principe sacro-saint pour les syndicats internationaux, la juridiction professionnelle exclusive. Selon ce principe, l'existence de deux ou de plusieurs syndicats rivaux dans un même métier affaiblissait le pouvoir de négociation du syndicat international dans le rapport de force qui l'opposait au patronat. Était donc combattue sans relâche toute organisation qui divisait les travailleurs d'un même métier. Ce principe, cher aux internationaux, n'était pas encore partagé par le CMTC qui ouvrait ses portes à toutes les organisations ouvrières canadiennes depuis sa fondation.

Plusieurs tentatives par des syndiqués internationaux pour exclure du CMTC des organisations rivales (Chevaliers du travail, Conseil central de Montréal) avaient fait l'objet de débats à chacun des congrès depuis $1899^{25}$. Au congrès de 1902 qui se tint à Berlin (Kitchener), un élément nouveau s'ajouta au dossier: le président d'une fédération internationale, John Tobin, prit la tête d'un mouvement pour exclure une organisation purement canadienne. Les syndicats internationaux au Canada répondirent nombreux à son appel: des 152 délégués au congrès (59 de plus qu'au congrès précédent), la majorité appartenait à des syndicats ayant une affiliation internationale ${ }^{26}$. Présent dans la salle du congrès, quoique sans droit de vote, Tobin était accompagné de 13 membres canadiens de l'Union internationale, dont les syndicats avaient pris soin d'envoyer au congrès le maximum de délégués permis par la constitution. La fédération avait pris en charge les frais de voyage de ces délégués $(250,00$ \$ pour les délégués montréalais uniquement) $)^{27}$.

Dominé par les internationaux, le Congrès modifia sa constitution dans le sens demandé par les délégués de l'Union internationale. La nouvelle constitution n'autorisait plus désormais l'admission d'un syndicat sans affiliation internationale à moins qu'il n'existât aucune fédération du métier concerné. Même dans ce cas, la constitution faisait obligation à ce syndicat de joindre toute nouvelle fédération internationale qui pourrait voir le jour dans ce

24 Circulaire envoyée aux syndicats internationaux au Canada, J. Tobin et C.L. Baine, Boston, 20 juillet 1902, The Shoe Workers'Journal, août 1902, 21.

25 J. Rouillard, op. cit., 68-71.

26 Canadian Trades and Labor Congress, Proceedings (1902): 4-6.

27 Lettre de J. Tobin à l'exécutif, 28 juillet 1902, 10 septembre 1902, Archives de la BSWU, General Executive Board, Actions and Decisions. 
métier ${ }^{28}$. Rompant avec sa tradition d'ouverture envers tout syndicat canadien, le CMTC se plaçait à la remorque du mouvement ouvrier étatsunien. Cet événement qui consacrait la domination du mouvement ouvrier canadien par nos voisins du Sud était lié à la querelle intersyndicale parmi les ouvriers de la chaussure de Montréal.

Au retour du congrès, Tobin se félicitait du succès de l'opération; il n'ignorait pas cependant que l'expulsion de la Fédération canadienne des cordonniers ne signifiait pas sa disparition ${ }^{29}$. Comme nous le verrons plus bas, l'Union internationale eut fort à faire pour conserver ses syndicats montréalais. Résultat de deux années d'organisation, l'Union internationale disposait au lendemain du congrès de Berlin de trois syndicats affiliés au Québec, tous de Montréal, alors qu'elle en comptait sept en Ontario ${ }^{30}$. Elle possédait environ 150 membres à Montréal, surtout des tailleurs de cuir ${ }^{31}$.

L'implantation de l'Union internationale au Canada soulève une question fondamentale. Pourquoi l'Union internationale a-telle mis autant d'énergie à syndiquer les travailleurs canadiens? Organisation née aux Etats-Unis, pourquoi a-t-elle senti le besoin de s'adjoindre des travailleurs d'un pays différent? Les ouvrages les plus complets sur le syndicalisme international, ceux de Stuart Jamieson et de John Crispo, ont relevé la crainte de la concurrence des travailleurs canadiens moins bien rémunérés, la perspective d'accroître les effectifs, la communauté de langue et de culture entre les deux pays, le va-et-vient des travailleurs de part et d'autre de la frontière et, enfin, le désir manifesté par les Canadiens euxmêmes de renforcer leurs propres organisations syndicales ${ }^{32}$.

Pour la fédération qui nous intéresse, les Canadiens n'ont pas fait appel aux «Américains»; ce sont ces derniers qui, en 1900, ont décidé d'implanter leur fédération au Canada. Le président Tobin manifestait un intérêt particulier pour le Canada puisqu'il était né à Guelph en Ontario, qu'il y avait appris son métier de cordonnier et qu'il n'avait émigré aux États-Unis qu'à l'âge de 26 ans $^{33}$. Il

\footnotetext{
30 The Shoe Workers' Journal, décembre 1903.

31 Approximation à partir du nombre de Montréalais qui ont voté à l'élection de l'exécutif international (128) (Ibid., février 1903).

32 Stuart Jamieson, Industrial Relations in Canada (Toronto Macmillan, 1957), 64-67; John Crispo, International Unionism, a Study in Canadian American Relations Toronto, McGraw-Hill, 1967), 11-29.

33 The Times, 15 avril 1919.
} 60: $450-451$.

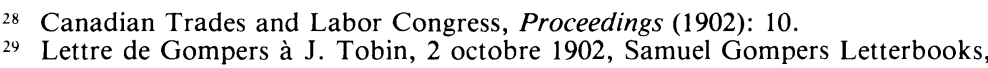


n'était d'ailleurs pas le seul Canadien à travailler dans l'industrie de la chaussure aux États-Unis: on sait, par exemple, que les Canadiens français composaient 5,7\% de la main-d'oeuvre de l'industrie de la chaussure en Nouvelle-Angleterre ${ }^{34}$, et que de nombreux Canadiens anglais avaient émigré aux États-Unis. À vrai dire, les lois d'immigration étaient très permissives à cette époque; on peut dire qu'il existait «un marché commun» de la main-d'oeuvre entre le Canada et les États-Unis. D'autre part, les travailleurs, au XIXe siècle, se déplaçaient souvent d'une ville à l'autre, ainsi que l'ont démontré Michael Katz et d'autres historiens «américains» ${ }^{35}$. Il n'était pas rare de voir un ouvrier changer trois ou quatre fois de localité au cours de sa vie.

Les salaires plus élevés aux États-Unis attiraient les Canadiens dans les villes industrielles américaines. Pour se protéger de cette main-d'oeuvre à bon marché en provenance du Canada, les chefs syndicaux «américains» ont pensé qu'il fallait relever les salaires ici même au Canada en intégrant à leurs syndicats les travailleurs canadiens. Ce motif semble avoir pesé lourd dans la décision de Tobin d'envoyer un organisateur au Canada. Un article du journal de la fédération, en novembre 1901, s’insurgeait contre la présence de syndicats indépendants au Québec:

It will result in a steady stream of migration of the best workmen of the Quebec factories to other sections of the Dominion and to the United States, and Quebec will be nothing but a school for green shoemakers, producing shoes unfit to be seen and still more unfit to be worn. ${ }^{36}$

Le Québec étant devenu un centre important de fabrication de chaussures, on comprend que les syndicalistes étatsuniens aient voulu se prémunir contre la concurrence aux États-Unis des travailleurs d'origine québécoise.

La crainte que les industries canadiennes exportent aux ÉtatsUnis des chaussures vendues à meilleur marché à cause d'un plus faible coût de la main-d'oeuvre aurait pu constituer une raison supplémentaire de syndiquer les ouvriers canadiens. Mais, à l'époque, le Canada n'exportait presque pas de chaussures aux États-

34 U.S. Bureau of the Census, Special Reports, Occupations at the Twelfth Census, 1900, 220-423, dans R.D. Vicero, Immigration of French Canadians to New England, 1840-1900: A Geographical Analysis, Ph. D. Thesis (The University of Wisconsin, 1968), 298.

35 M.B. Katz, The People of Hamilton, Canada West, Family and Class in a MidNineteenth Century City (Cambridge, Harvard University Press, 1975), 17-24. Pour une bibliographie extensive à ce sujet, voir 353-372.

${ }_{36}$ The Shoe Workers' Journal, novembre 1901, 13. 
Unis; c'est plutôt le contraire qui se produisait puisque les marchands canadiens achetaient aux Etats-Unis 5\% des chaussures vendues au Canada ${ }^{37}$. C'est pourquoi les manufacturiers canadiens, et même les syndicats de la chaussure, réclamaient du gouvernement une meilleure protection tarifaire ${ }^{38}$.

La perspective d'un accroissement de ses effectifs a certainement contribué à éveiller l'intérêt de l'Union internationale pour le Québec. Comme nous le signalions précédemment, elle ne possédait que 10000 membres en 1901, à l'époque où un de ses organisateurs traversa la frontière. Les milliers de travailleurs de la chaussure des villes proches de la frontière étatsunienne ne pouvaient que susciter sa convoitise. D'ailleurs, les organisateurs internationaux répétaient constamment qu'un syndicat n'était fort que dans la mesure où ses effectifs étaient nombreux: «Plus une organisation, bonne en soi, est répandue, plus elle a de force et d'efficacité; meilleure elle est.» ${ }^{39}$ L'idéologie même de la fédération internationale lui commandait de recruter le plus grand nombre de membres possible. En effet, puisqu'elle concevait ses relations avec le patronat dans un esprit de rapport de force, le nombre lui conférait un meilleur pouvoir de marchandage car il signifiait une structure plus solide, un meilleur encadrement et un fonds de grève plus important. Lorsque venait le temps de choisir une affiliation syndicale, c'est l'argument qui avait le plus de poids auprès des travailleurs québécois.

Il est bon enfin de signaler que l'Union internationale aurait pu difficilement prendre pied à Montréal si elle n'avait pu compter sur l'appui de dirigeants syndicaux locaux appartenant à d'autres fédérations internationales. Aux premières assemblées destinées à faire connaître l'Union internationale, il y avait souvent plusieurs orateurs bien connus des Montréalais qui vantaient les mérites de l'affiliation internationale. En s'adressant aux travailleurs en français, ils atténuaient le caractère étranger de l'organisation et témoignaient de la solidarité des syndicats internationaux à Montréal. Sans cet appui, plusieurs fédérations internationales n'auraient jamais vu le jour au Québec.

\section{Expansion et relations intersyndicales}

Fondée en novembre 1901 pour faire échec à l'Union internationale, la FCC se coalisa avec l'Association des manufacturiers de

37 Canada, Recensement du Canada (1901), III: 287; Documents de la Session, 39, 4, (1905): 80-81.

38 The Shoe Workers' Journal, novembre 1904, 16.

39 Ibid., août 1902, 21. 
chaussures de Montréal pour enrayer son expansion. Des pourparlers entre patrons et syndicats pour régler à l'amiable les conflits de travail avaient eu cours dans la métropole depuis 1901. C'est Mgr Bruchési, archevêque de Montréal, qui en avait suggéré l'idée, reprenant à son compte le mode d'arbitrage mis au point par $\mathrm{Mgr}$ Bégin à Québec ${ }^{40}$. Aux prises avec deux groupes de syndiqués qui réclamaient l'atelier syndical, l'Association des manufacturiers donna la préférence à la FCC. C'était, écrivait un manufacturier dans $L a$ Presse, "le meilleur moyen de favoriser les bonnes relations entre le capital et le travail, car on s'entend toujours mieux avec un compatriote qu'avec un étranger» ${ }^{41}$. Et un travailleur, membre de la fédération internationale, de répliquer quelques jours plus tard dans une lettre au journal:

$\mathrm{Si}$, au lieu d'être ouvrier, nous étions patrons, il est très probable que nous serions exactement de son avis. Moins les organisations ouvrières sont puissantes, moins elles ont de moyens de défense, plus cela fait naturellement l'affaire des employeurs. ${ }^{42}$

Espérant sans doute trouver dans la FCC un syndicat plus conciliant, l'Association des manufacturiers combattit donc l'Union internationale dans la métropole.

La Fédération canadienne trouva là un précieux allié quoique ce ne soit pas la seule raison qui explique ses progrès pendant ses premières années d'existence. En 1903, elle disait compter dix syndicats et 1700 membres, chiffres probablement exagérés, mais qui révèlent de toute façon des effectifs de beaucoup supérieurs à ceux de l'Union internationale dans la métropole (approximativement 150 membres) ${ }^{43}$.

Mais celle-ci n'abandonna pas la partie: «we have never moved from a place when we have once planted our flag there», écrivait Tobin ${ }^{44}$. La Fédération engagea pour quelques mois un organisateur bilingue et versa plusieurs contributions financières spéciales à ses syndicats montréalais. Et surtout, son président entreprit une vaste campagne de persuasion auprès des manufacturiers, pour leur vanter les avantages de la marque syndicale internationale. A défaut de s'allier les travailleurs directement, Tobin misait sur l'aide des patrons pour vaincre la résistance des employés.

\footnotetext{
40 La Presse, 5 juin $1901,10$.

41 Lettre de M. Tétreault au journal, 22 mai 1902, La Presse, 31 mai 1902, 2.

42 Lettre d'un cordonnier au journal, 3 juin 1902, La Presse, 4 juin 1902, 7.

43 La Presse, 15 octobre 1903, 5; The Labour Gazette, mars 1904, 949.

44 Archives de la BSWU, General Executive Board, 7 avril 1903.
} 
À la fin de 1902, deux entreprises montréalaises seulement utilisaient l'étiquette internationale ${ }^{45}$. L'année suivante, une compagnie importante, la maison Slater, qui employait 500 ouvriers, se laissa convaincre, pour pouvoir marquer ses chaussures de cette étiquette, de reconnaitre le syndicat international comme seul représentant de ses employés. Comme ces travailleurs appartenaient à la FCC, ils refusèrent de se plier à la directive de la compagnie de changer d'allégeance syndicale ${ }^{46}$; une centaine d'entre eux se mirent alors en grève, mais sans réussir à ébranler la compagnie qui put compter sur l'Union internationale pour remplacer les grévistes. Non sans difficulté, car elle dut faire venir une cinquantaine de cordonniers-monteurs des États-Unis ${ }^{47}$. En 1905, un autre gros manufacturier, la compagnie J. et T. Bell, mit en demeure ses employés de briser leur attache avec la FCC pour adhérer à l'Union internationale ${ }^{48}$. Cette année-là, cinq des plus importants manufacturiers montréalais utilisaient l'étiquette internationale.

Quoique ces manufacturiers aient invoqué «les désagréments et du trouble» qu'ils auraient subis de la part de la FCC pour lui préférer l'Union internationale, il semble plutôt que leur volte-face provient des difficultés qu'ils auraient éprouvées à vendre leurs chaussures en Ontario et dans l'Ouest canadien parce qu'elles ne portaient pas la marque internationale. Un article de l'organe de l'Association des manufacturiers canadiens faisait référence à ce problème en décembre $1904^{49}$. Il apparait donc que les manufacturiers ont fait passer leur désir de mousser leurs ventes avant la crainte que l'Union internationale pouvait leur inspirer. Leur revirement confirme le succès de l'étiquette syndicale comme moyen de pression sur le patronat. La publicité faite à la marque syndicale parmi les travailleurs canadiens appartenant aux syndicats internationaux apportait des dividendes à l'Union internationale.

Aux prises avec une hémorragie de ses membres et désireuse de refaire l'unité des travailleurs, la FCC proposa en 1909 un référendum parmi les cordonniers pour éliminer une des deux organisations dans la métropole ${ }^{50}$. L'agent d'affaires de l'Union internationale à Montréal, Z. Lespérance, s'y opposa, expliquant que les membres de son association étaient satisfaits de leur organisation. «Les capitalistes, disait-il, ont l'argent pour combattre les unions ouvrières, et (...) celles-ci, pour répondre à cette force, n'ont que

\footnotetext{
4 The Shoe Workers' Journal, août 1902, 34.

Les Débats, 26 juillet 1903, 2.

La Presse, 15 octobre 1905, 5; The Shoe Workers' Journal, février 1904, 9.

48 La Patrie, 4 mai 1905, 3; The Shoe Workers' Journal, août 1905, 45.

49 Industrial Canada, décembre 1904, 327.

so La Patrie, 5 novembre 1909, 3.
} 
leur nombre à y opposer ${ }^{51}$. L'Union internationale, ajoutait-il, ayant près de 100000 membres, représentait le meilleur moyen de pression sur le patronat. Les travailleurs n'étaient pas insensibles à cet argument. La FCC, avec quelques centaines de membres, ne parvenait pas à offrir des services comparables à ceux des syndicats internationaux: assurance-maladie, assurance-vie, fonds de grève, etc. Le bassin de travailleurs qu'elle recrutait n'était pas suffisant pour mettre sur pied de tels services; il aurait pu en être autrement si les travailleurs de Québec l'avaient rejointe; mais ce ne fut pas le cas pour des raisons que nous évaluerons plus loin.

À la recherche de cette force qui leur faisait défaut, les dirigeants de la FCC passèrent armes et bagages en 1911 à une fédération internationale rivale de l'Union internationale des travailleurs en chaussures, les Travailleurs unis de la chaussure d'Amérique (United Shoe Workers of America). C'est à la suite d'une assemblée convoquée par l'organisateur de cette fédération que la décision fut prise, sans que la majorité des membres ne fût consultée ${ }^{52}$. Quatre syndicats comptant environ 600 membres (peut-être moins) rejoignirent ainsi cette fédération née à Lynn (Massachusetts) en 1909, à la suite de dissensions à l'intérieur de l'Union internationa$\mathrm{le}^{53}$.

Non sans raison, les auteurs du schisme aux États-Unis reprochaient à l'Union internationale de faire reposer le syndicalisme davantage sur l'appui des patrons que sur le militantisme des ouvriers. En effet, l'insistance mise par la fédération sur la marque syndicale l'avait conduite à recruter ses membres en sollicitant plus le support des patrons que celui des ouvriers. Il en était résulté, soutenait-on, un mouvement syndical conservateur, plus intéressé à garder l'appui des patrons que désireux d'améliorer la condition des travailleurs. L'aile dissidente reprochait en outre à l'exécutif de faire peu d'efforts pour recruter des membres, de ne pas se soucier d'améliorer les conditions de travail des syndiqués, d'éviter d'utiliser la grève et, en fin de compte, d'être coupée de la base syndica$\mathrm{le}^{54}$. Si on se réfère aux méthodes d'organisation de la fédération à Montréal, ces reproches sont largement fondés.

51 Ibidem.

52 Selon l'organe de l'Union internationale, il n'y avait que 40 personnes à cette assemblée (The Shoe Workers' Journal, avril 1912, 11).

53 United Shoe Workers of America, Proceedings (1911): 7. L'organe de l'Union internationale soutenait que les Travailleurs unis avaient moins de cent membres en règle à Montréal parmi les deux cents qui l'appuyaient (The Shoe Workers' Journal, mai 1911, 24).

54 A.G. Erlando, "Lest we Forget»: A Review of a Few Important Events in the Development of a Labor Union in the Shoe Industry, pamphlet de la USWA (1914), 16 p.; A.E. Galster, The Labor Movement in the Shoe Industry (New York, Ronald Press, 1924), 110-114. 
Les quatre nouveaux syndicats montréalais des travailleurs unis conservèrent peu de temps leur affiliation. À la fin de l'année 1911 , le journal Le Soleil annonçait leur dissolution ${ }^{55}$. Ce qui semble avoir donné un coup mortel à ces syndicats, c'est la décision de la plus grosse compagnie de chaussures de Montréal, la firme Ames-Holden-McCready, d'utiliser la marque syndicale de l'Union internationale. Cette entreprise était née peu auparavant de la fusion de deux compagnies, la firme Ames-Holden qui possédait la marque syndicale internationale depuis 1901 et la firme McCready qui avait reconnu la FCC. En jetant son dévolu sur l'Union internationale, la nouvelle compagnie lui apportait de nouveaux membres qu'elle arrachait aux Travailleurs unis. L'organisateur de cette dernière fédération essaya en vain d'obtenir de la compagnie l'atelier ouvert; un groupe de monteurs déclencha une grève dans ce but, mais sans succès, leurs places étant comblées aussitôt grâce aux bons offices de l'Union internationale ${ }^{56}$. Ce dernier événement, qui confirme le rôle capital du patronat dans les succès de l'Union internationale, faisait de cette fédération la seule organisation à Montréal parmi les ouvriers de la chaussure. Plusieurs travailleurs se rallièrent alors à l'Union internationale si bien qu'en 1913 elle possédait 1500 membres dans la métropole.

C'est durant la guerre qu'elle a recruté le nombre le plus élevé de syndiqués montréalais. Selon des estimations grossières, environ le tiers des travailleurs de la chaussure à Montréal faisait partie de l'Union internationale en $1918^{57}$. Pour les années antérieures, ce pourcentage était évidemment beaucoup plus faible.

Avant la guerre, l'Union internationale tenta à quelques reprises de déborder la région montréalaise. En 1901, elle avait formé un syndicat à Saint-Hyacinthe, après que la compagnie SéguinLalime eût accepté la marque syndicale internationale ${ }^{58}$. Ce syndicat connut une vie brève puisque dès l'année suivante, l'Union internationale retirait à la compagnie l'étiquette syndicale parce qu'elle ne se conformait pas aux règles de la fédération ${ }^{59}$. La FCC eut pendant un certain temps dans cette ville, un syndicat qui disparut avec la débâcle de la fédération à Montréal ${ }^{60}$. L'Union internationale reprit pied à Saint-Hyacinthe en 1908 à la demande de la

55 Le Soleil, 28 décembre 1911, 7.

56 The Shoe Workers'Journal, septembre 1911, 10; avril 1912, 11.

571400 syndiqués sur 4000 travailleurs montréalais (Annuaire statistique du Québec (1920): 357-359.

58 Rapport des séances de l'Union protectrice des coordonniers-monteurs, 10 avril 1901, Archives de l'Université Laval, Fonds de L'U.P.C.M., 290, 1, bobine 5.

59 La Presse, 21 février 1902, 9.

60 La Gazette du Travail, mars 1904, 949. 
TABLEAU I

UNITÉS SYNDICALES ET EFFECTIFS DE L'UNION INTERNATIONALE DES OUVRIERS DE LA CHAUSSURE ${ }^{61}$

\begin{tabular}{lcccc} 
& \multicolumn{2}{c}{ UNITÉS SYNDICALES } & \multicolumn{2}{c}{ EFFECTIFS } \\
\cline { 2 - 5 } & Québec & Canada & Québec & Canada \\
\hline 1901 & 4 & - & - & - \\
1902 & 4 & 9 & - & - \\
1903 & 4 & 8 & - & - \\
1904 & 4 & 8 & - & - \\
1905 & 4 & 8 & - & - \\
1906 & 3 & 8 & - & 1307 \\
1907 & 3 & 10 & - & - \\
1908 & 4 & 12 & - & - \\
1909 & 4 & 11 & 1100 & - \\
1910 & 5 & 14 & 1200 & 2246 \\
1911 & 6 & 16 & 1500 & 1817 \\
1912 & 7 & 15 & 1200 & 1752 \\
1913 & 5 & 16 & 1500 & 2000 \\
1914 & 5 & 15 & 1500 & - \\
1915 & 5 & 16 & 1500 & 3254 \\
1916 & 5 & 19 & & \\
1917 & 5 & & &
\end{tabular}

compagnie Ames-Holden de Montréal qui venait d'y ouvrir une manufacture ${ }^{62}$. Ce syndicat, quoiqu'il ait compté peu d'adhérents, survécut jusqu'en 1947.

A Trois-Rivières où était implantée une fabrique de chaussures, la compagnie Tebbutt Shoe, la venue de l'Union internationale eut des conséquences importantes. En septembre 1912, les ouvriers de cette usine qui se plaignaient de leurs conditions de travail formèrent un syndicat sous l'égide de l'Union internationale. Lorsqu'ils présentèrent au propriétaire une demande d'augmentation de salaires $(15 \%)$, M. Tebbutt congédia tous les employés syndiqués $^{63}$. Il refusa de rencontrer l'agent d'affaires $(Z$. Lespérance) et le vice-président de l'Union internationale (C. Lovely) qui offraient leur médiation. Bien que le syndicat fût de formation

61 Canada, Ministère du Travail, La Gazette du Travail, 1901-1911; Organisation des Travailleurs au Canada, 1911-1919. Pour 1907, les effectifs sont tirés de La Patrie, 18 juin 1907, 6 et Archives de la UITC, Report of the Proceedings of the General Executive Board, 17 juin 1907 .

62 La Patrie, 24 novembre 1908, 3; 18 mars 1910, 3.

63 Lettre de Z. Lespérance à C.L. Baine, 23 octobre 1912, Archives de la BSWU, General Executive Board, Actions and Decisions. 
récente, la fédération versa des prestations de grève pendant deux mois aux travailleurs de Trois-Rivières. Les grévistes, au nombre d'une quarantaine, surtout des tailleurs de cuir, parvinrent presque à paralyser le fonctionnement de l'usine. Après avoir essayé sans succès de recruter des tailleurs à Québec et à Montréal, le propriétaire se tourna du côté du curé de la paroisse pour qu'il convainque les ouvriers de retourner au travail ${ }^{64}$. Le curé rencontra les ouvriers et il montra, selon leurs dires, de la sympathie pour leur syndicat et leurs réclamations ${ }^{65}$. Mais l'évêque du lieu, Mgr Cloutier, réagit fort différemment.

Prenant conscience du «péril international», Mgr Cloutier s'empressa de mettre sur pied des syndicats confessionnels «pour arracher les ouvriers aux Unions neutres» ${ }^{66}$. Après avoir prononcé quelques conférences sur la doctrine sociale de l'Église, il mit sur pied la Corporation ouvrière catholique de Trois-Rivières, organisme qui devait coiffer les syndicats catholiques à TroisRivières ${ }^{67}$. À peu près à la même époque, la crainte de la Fraternité internationale des charpentiers inspirait aux évêques de Chicoutimi et de Québec la formation de syndicats confessionnels dans leurs diocèses ${ }^{68}$. À Trois-Rivières, cet intérêt nouveau du clergé pour le syndicalisme signifia l'arrêt de mort du syndicat international de la chaussure. Certains de ses membres joignirent le syndicat catholique nouvellement fondé alors que d'autres qui voulaient rester fidèles à l'allégeance internationale, gagnèrent Montréal ${ }^{69}$. Ce n'était pas la première fois que l'Union internationale avait maille à partir avec le clergé catholique.

On se rappellera que la constitution imposée par l'archevêque aux trois syndicats de la chaussure de Québec leur interdisait en fait une affiliation internationale. Très tôt, l'Union internationale a réalisé qu'elle ne délogerait pas facilement les syndicats de Québec et qu'il valait mieux entretenir de bons rapports avec eux. Avant la guerre, elle s'est donc abstenue d'envoyer des organisateurs à Québec. Les syndicats de la Vieille capitale conservaient pendant ce temps leur neutralité dans la bataille opposant la FCC à l'Union internationale à Montréal. Il est significatif qu'à l'occasion d'une grève des internationaux à Montréal, en 1905, le syndicat des tailleurs de cuir de Québec ait voté une résolution défen-

\footnotetext{
64 Lettre de Z. Lespérance à C.L. Baine, 30 octobre 1912, ibid.

65 Lettre de Z. Lespérance à C.L. Baine, 8 novembre 1912 , ibid.

${ }_{66}$ Allocution de Mgr Cloutier (sans date), Dossier Questions civiles et sociales, Archives de l'évêché de Trois-Rivières

67 J. Rouillard, op. cit., 191-192.

68 Ibid., 190 et 196.

69 Archives de la BSWU, Report of the Proceedings of the General Executive Board, 28 octobre 1912 .
} 
dant à ses membres sous peine d'amende ou d'expulsion d'aller travailler à Montréal ${ }^{70}$. Le syndicat de Québec refusait de jouer le rôle de briseur de grève, ce à quoi l'invitait pourtant la Fédération canadienne ${ }^{71}$.

Ces bonnes relations ont changé rapidement à mesure que les syndicats de Québec ont accentué leur caractère confessionnel et qu'ils ont voulu propager «la bonne nouvelle» à Montréal. Grâce au travail de l'abbé Fortin, qui mit sur pied en 1915 un Cercle d'études destiné à diffuser la doctrine sociale de l'Église parmi les travailleurs de Québec, les syndicats de la chaussure acceptèrent deux ans plus tard de devenir des organisations «ouvertement et franchement catholiques $)^{72}$. Fort de leur nouvel idéal, ils tentèrent une première incursion à Montréal en 1918, alléguant l'apathie de l'Union internationale à répondre aux attentes des travailleurs ${ }^{73}$. La nouvelle organisation, à laquelle ils donnèrent le nom d'Union des travailleurs industriels de la chaussure, visait une clientèle délaissée par les «internationaux», les travailleuses de la chaussure. L'initiative réveilla l'Union internationale à la présence de ce groupe délaissé; elle lançait un peu plus tard une campagne d'organisation parmi les ouvrières ${ }^{74}$. En juin 1919, l'Union des travailleurs industriels fut prise en charge par l'abbé Edmour Hébert, que l'évêché avait nommé depuis peu responsable des oeuvres sociales à Montréal. Il avait fondé un cercle d'études et se proposait de former des syndicats catholiques. Son travail d'organisation commença précisément parmi les travailleurs de la chaussure, qu'il attira en grand nombre dans les rangs du syndicat. Comme le faisaient les «internationaux», il fit la tournée des manufacturiers pour solliciter leur encouragement ${ }^{75}$. Après quelques mois d'efforts, le syndicat disait compter 1000 membres, ce qui est probablement exagéré $^{76}$. En 1920, ce syndicat s'écarta de la confessionnalité, mais il revint dans le giron du syndicalisme catholique, trois ans plus tard.

À partir de ce moment, le syndicalisme catholique prit assez d'expansion dans la chaussure à Montréal pour diviser les travailleurs en cinq syndicats de métier, avec un bureau exécutif général pour coordonner leur action. En 1926, 600 travailleurs versaient

70 La Presse, 16 novembre 1915, 9. L'Union internationale retourna à ses frais trente tailleurs de Québec que les manufacturiers avaient réussi à attirer à Montréal (Lettre de J. Tobin à l'exécutif, 28 novembre 1905, Archives de la UTOC, General Executive Board, Actions and Decisions).

71 Ibid.

72 J. Rouillard, op. cit., 208.

73 Le Soleil, 26 août 1918, 5; La Presse, 11 septembre 1918, 13.

74 Le Monde Ouvrier, 26 juillet 1919, 2.

75 G. Tremblay, «Le syndicalisme catholique à Montréal» dans L'Organisation ouvrière catholique au Canada (École Sociale Populaire no 105, Montréal, ESP), 19.

76 Ibidem. 
régulièrement leur cotisation ${ }^{77}$; ce nombre est resté assez stable jusque dans les années quarante.

TABLEAU II

EFFECTIFS SYNDICAUX DE L'UNION INTERNATIONALE ET DES SYNDICATS CATHOLIQUES DE LA CHAUSSURE ${ }^{78}$

\begin{tabular}{|c|c|c|c|c|}
\hline \multirow{2}{*}{ ANNÉE } & \multicolumn{2}{|c|}{ UNION INTERNATIONALE } & \multicolumn{2}{|c|}{ SYNDICATS CATHOLIQUES } \\
\hline & à Montréal & au Canada & à Montréal & au Québec \\
\hline 1920 & 1500 & 2961 & - & - \\
\hline 1921 & 1500 & 2091 & - & - \\
\hline 1922 & 1500 & 1641 & - & - \\
\hline 1923 & 850 & 1707 & - & - \\
\hline 1924 & 1000 & 1734 & - & - \\
\hline 1925 & 1000 & 1714 & - & - \\
\hline 1926 & 1000 & 1438 & 600 & - \\
\hline 1927 & 1200 & 1322 & - & - \\
\hline 1928 & 1200 & 1127 & - & - \\
\hline 1929 & 900 & 1113 & - & - \\
\hline 1930 & 1200 & 1114 & 719 & - \\
\hline 1931 & 1200 & 1053 & - & - \\
\hline 1932 & - & 896 & - & - \\
\hline 1933 & - & 1842 & - & - \\
\hline 1934 & - & 1425 & - & 4000 \\
\hline 1935 & - & 1425 & 700 & 4547 \\
\hline 1936 & - & 1306 & - & 3890 \\
\hline 1937 & - & 1091 & 800 & 3950 \\
\hline 1938 & - & 1500 & 785 & 4000 \\
\hline 1939 & - & 1500 & - & 3000 \\
\hline 1940 & - & 1500 & 400 & 2800 \\
\hline
\end{tabular}

En 1931, la CTCC fonda une Fédération nationale et catholique des travailleurs de la chaussure, fédération qui regroupait les syndicats de Québec et de Montréal. C'est à ce moment qu'elle s'implanta ailleurs en province: à Batiscan, Saint-Tite, Grand'Mère, Bagot, Beauceville et Saint-Jérôme. Ses effectifs se chiffraient alors entre 3000 et 4000 membres, soit plus du double

G. Tremblay, «Le Bilan de nos activités syndicales», Programme-Souvenir de la Fête du Travail, CTCC (1926), 19.

78 Canada, Ministère du Travail, Report on Labour Organization in Canada, 19261940. Ces données statistiques recueillies par le ministère fédéral du Travail ont été fournies par les syndicats eux-mêmes. Ces derniers ont tendance à gonfler leurs effectifs de sorte que ces chiffres donnent plus un ordre de grandeur qu'ils ne reflètent les effectifs réels des syndicats. Les données sur les effectifs canadiens sont plus proches de la réalité que les effectifs montréalais. 
de ceux de l'Union internationale qui resta cantonnée à Montréal et à Saint-Hyacinthe ${ }^{79}$.

La montée du syndicalisme catholique, après la guerre, ébranla l'Union internationale dans son château-fort de Montréal. Certains manufacturiers montréalais lui retirèrent leur appui et l'Association des manufacturiers de chaussures de Montréal résolut en 1921 de donner la préférence dans l'embauche aux syndiqués catholiques ${ }^{80}$. L'organisation des syndicats catholiques survenait au moment où l'industrie de la chaussure subissait une récession (1920-1925). La division des travailleurs et le chômage placèrent l'Union internationale dans une position de faiblesse dont s'empressèrent de profiter les manufacturiers.

En septembre 1919, la compagnie Slater lui retirait l'atelier fermé, son propriétaire arguant qu'il entendait «rester maître chez lui» et «employer qui il voulait» ${ }^{81}$. Le même scénario se produisit deux ans plus tard lorsque la compagnie Ames-Holden-McCready mit fin à une entente longue de vingt ans avec le syndicat international. Le président de la compagnie, T.H. Reider, ne se rappelait certainement pas les événements qui avaient amené l'Union internationale dans ses usines en 1901 lorsqu'il déclarait:

We decided to work open shop and deal direct with our men. Why should they get their orders from Boston? They would still be contentedly at work if it had not been for orders from Boston headquarters of the international union. ${ }^{82}$

L'Union internationale apprenait à ses dépens que son association avec les manufacturiers ne reposait pas sur des sentiments mais des intérêts. Pour éviter le pire, elle recula après quelques jours de grève dans ces deux entreprises, acceptant des diminutions de salaire et l'atelier ouvert.

La marque syndicale internationale n'avait plus le même attrait pour les manufacturiers. L'Union internationale essaya bien de faire connaître la marque syndicale parmi les travailleurs, mais sans beaucoup de succès ${ }^{83}$. Après la guerre, la plupart des fédérations internationales accordèrent de moins en moins d'importance à la marque syndicale de sorte que peu de publicité était faite pour inciter les travailleurs à acheter les produits portant cette marque. Pour l'Union internationale qui en avait fait le principal moyen de recrutement de ses membres, ce changement eut des con-

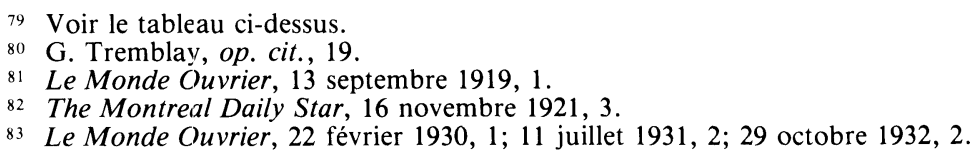


séquences dramatiques. Dans les années vingt, ses effectifs chutèrent brutalement aux États-Unis. Au Canada et au Québec, il y eut aussi déclin, quoique d'une ampleur moindre.

Pour compenser ses pertes à Montréal, l'Union internationale tenta à quelques reprises de percer à l'extérieur de la métropole. Son incursion à Québec en 1931, à la demande des travailleurs euxmêmes selon l'organisateur L. Thibeault, déclencha une vigoureuse riposte des syndicats catholiques. L'aumônier général, l'abbé Maxime Fortin, l'accusa d'être une association de "scabs», de vouloir faire baisser les salaires à Québec et de posséder comme tous les syndicats internationaux des tendances anticléricales et socialistes ${ }^{84}$. L'organisateur réfuta ces attaques sans pouvoir pour autant empêcher son nouveau syndicat de disparaître dans les mois qui suivirent ${ }^{85}$. Sa déception fut aussi amère dans le cas du syndicat qu'il fonda à Grand'Mère en 1937. Celui-ci venait à peine d'être formé, qu'on organisa un syndicat catholique pour lui faire échec. Un des orateurs à l'assemblée des travailleurs organisée pour faire ressortir les bienfaits du syndicalisme international déclarait que «l'union ouvrière n'était pas une confrérie, mais une organisation ayant pour but de relever les conditions d'existence des ouvriers». Les syndicats catholiques, soutenait-il, divisaient les travailleurs au profit du patronat et acceptaient des salaires moindres que les «internationaux» ${ }^{86}$. Le syndicat fut dissous la même année.

Les syndicats catholiques avaient fait de la province, à l'extérieur de Montréal, une chasse-gardée où il devenait de plus en plus difficile pour l'Union internationale de s'implanter. C'était grave pour cette fédération car, dans les années trente, l'industrie de la chaussure se déplaçait vers les centres ruraux. Les syndicats catholiques suivirent ce déplacement, alors que l'Union internationale était accueillie avec méfiance en province. C'est une des raisons qui explique la montée spectaculaire des effectifs de la CTCC de 1934 à 1940, alors que les «internationaux» ne progressaient que très lentement au Québec.

Il était assez délicat pour les «internationaux» de s'attaquer à des syndicats qui associaient la religion au syndicalisme et qui avaient l'appui du clergé. Auprès d'une population fortement catholique comme celle du Québec, ce n'était pas une mince tâche que de se faire le propagandiste du syndicalisme international. Dans les assemblées d'organisation et les articles de journaux vantant les mérites de l'Union internationale, on attaquait rarement le

\footnotetext{
84 Ibid., 10 octobre $1931,1$.

85 Ibid., 17 octobre 1931, 2.

86 Ibid., 15 mai 1937, 3.
} 
syndicalisme catholique directement; on préférait plutôt mettre l'accent sur les avantages du syndicalisme international pour les travailleurs. C'était, disait-on, «la seule (organisation) qui protégeait efficacement les travailleurs, car elle seule a la force voulue pour traiter avec avantage avec les patrons» ${ }^{87}$; ou encore, revenait souvent l'idée que la division des travailleurs profitait aux employeurs ${ }^{88}$. Ces raisonnements avaient leur poids, mais ils ne parvenaient pas à dissiper l'appréhension nourrie par le clergé à l'égard de l'Union internationale.

Toutefois, malgré quelques accrochages, les deux mouvements vécurent en relative harmonie. En quelques occasions, ils mirent de côté leur rivalité pour collaborer à l'amélioration du sort des travailleurs. Ainsi, lors de la célèbre grève des syndicats catholiques de Québec, en 1925-1926, des représentants de l'Union internationale défendirent, à la demande de la CTCC, la cause des travailleurs de la chaussure devant un tribunal d'arbitrage ${ }^{89}$. Plus tard, ces deux mouvements essayèrent d'établir ensemble des demandes syndicales minimales pour l'industrie de la chaussure ${ }^{90}$. Ce qui semble avoir contribué le plus à une meilleure entente entre les deux mouvements, ce fut la formation du comité paritaire de la chaussure dans la foulée de la loi d'extension juridique (1934). Cette loi eut comme conséquence positive de faire travailler côte à côte des militants catholiques et des syndiqués internationaux. Ceux-ci ont sûrement réalisé à cette occasion que les deux mouvements n'étaient pas tellement éloignés l'un de l'autre et que les deux recherchaient en définitive l'avancement de la classe ouvrière.

\section{Les relations avec la Fédération internationale}

Les syndicats québécois ont entretenu des relations suivies avec le Bureau exécutif de l'Union internationale (le siège social était situé à Boston). Dans leur lutte contre les syndicats nationaux, les «internationaux» ont toujours fait valoir que l'affiliation internationale apportait des bénéfices considérables. Elle leur garantissait un appui financier et des services qu'un syndicat canadien ne pouvait s'offrir. Dans le rapport de force qui les mesurait au patronat, le lien international, soutenait-on souvent, procurait au syndicat une assistance qui faisait la différence entre une victoire et un échec. En revanche, les syndicats canadiens faisaient beaucoup de cas des sommes considérables versées en cotisation par-delà la

\footnotetext{
87 Ibid., 30 août 1930, 2.

88 Ibid., 26 juin 1937, 3; 8 juillet 1939, 2 .

89 Ibid., 17 octobre 1931, 2.

90 Ibid., 22 août 1936, 3.
} 
frontière. Les sommes envoyées à l'exécutif international, disaientils, dépassaient largement ce que les Canadiens pouvaient recevoir en retour. Voyons donc, ce qu'il en est, dans le cas particulier qui nous intéresse.

\section{a) Structure}

Les structures de l'Union internationale comprenaient à la base le syndicat local qui, pour recevoir une charte, devait compter au moins sept travailleurs ${ }^{91}$. Certains de ces syndicats étaient mixtes, c'est-à-dire qu'ils regroupaient des ouvriers de métiers différents. Quand ils étaient composés de travailleurs d'un même métier, il ne pouvait exister plus d'un syndicat de ce métier par ville. Â Montréal, le nombre de syndiqués justifiait l'existence de plusieurs unités syndicales; il y en eut de trois à cinq selon les périodes. Le «local» 249 , le plus vieux syndicat, se composait de tailleurs de cuir, les «locaux» 266 et 428 comprenaient des cordonniers-monteurs et le 549 des réparateurs de machines; les autres «locaux» semblent avoir regroupé plusieurs catégories d'ouvriers. En 1932, la faible participation des travailleurs aux assemblées syndicales a forcé l'Union internationale à dissoudre certains syndicats pour n'en garder qu'un seul, le 249 , qui réunit dès lors tous les syndiqués montréalais ${ }^{92}$.

Le droit d'entrée au syndicat était de 1,00 \$ par membre et la cotisation de 25 sous par semaine, ce qui était un montant assez élevé puisque la cotisation annuelle représentait deux semaines de travail en 1901. Le niveau de cotisation demeura le même jusqu'en 1939, alors qu'on l'augmenta à 35 sous, l'Union internationale ne parvenant pas à rencontrer ses obligations au titre des bénéficesdécès ${ }^{93}$. Selon la constitution, les deux tiers des sommes perçues par le «local» étaient acheminés au Bureau exécutif ${ }^{94}$.

Le nouveau membre, qui devait recevoir l'appui de la majorité des syndiqués du «local» pour être admis, prêtait serment d'assister aux réunions mensuelles du syndicat, d'accomplir ses devoirs de syndiqué, d'acheter des produits portant la marque syndicale et de faire tout en son pouvoir pour promouvoir les intérêts de l'Union internationale 95 . Le «local» pouvait imposer une amende ne dépassant pas $50,00 \$$ pour toute dérogation à ces devoirs ${ }^{96}$. L'achat de chaussures ne portant pas l'étiquette internationale

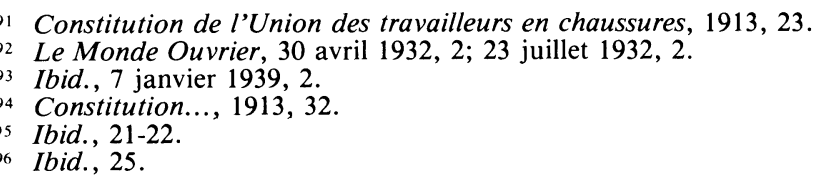


entraînait automatiquement une amende de 2,00 \$, montant qui fut augmenté à 5,00 $\$$.

Lorsqu'il y avait plus d'un syndicat dans une ville, la constitution leur permettait de créer un conseil conjoint chargé de planifier les demandes syndicales, de tenter de régler les conflits de travail et de faire la promotion de l'étiquette syndicale ${ }^{98}$. Dans la métropole, le conseil conjoint no 17, créé en 1901, a joué un rôle important de liaison entre les «locaux» et le Bureau exécutif.

Le Comité exécutif général comprenait un président, un viceprésident et huit autres membres élus à tous les deux ans lors d'un congrès de délégués provenant de chaque «local» ${ }^{99}$. John F. Tobin accomplit la tâche de président de 1895 à 1919; Collis Lovely et John Mara lui succédèrent. Entre 1902 et 1951, il y a toujours eu un Québécois au sein du Comité exécutif: Alphétus Mathieu de 1902 à 1929 et Charles McKercher jusqu'en 1951. Ces trois Montréalais étaient en même temps agents d'affaires de l'Union internationale au Canada.

La révision de la constitution en 1899 augmenta sensiblement les pouvoirs de l'exécutif dont la faiblesse, disait-on, avait été responsable des difficultés de la fédération depuis sa fondation. C'était le Bureau exécutif, et non le syndicat local, qui décidait de l'attribution de la marque syndicale; le mode d'arbitrage des conflits était uniforme pour tous les syndicats et l'approbation du Bureau nécessaire pour obtenir de l'assistance financière en cas de grève ${ }^{100}$. Sur toutes les questions pour lesquelles la constitution ne prévoyait rien de précis, le Bureau exécutif avait pleine autorité ${ }^{101}$. En ce qui touche le délicat sujet des demandes salariales, le syndicat local déterminait lui-même avec le conseil conjoint les réclamations qu'il ferait aux manufacturiers ${ }^{102}$. La correspondance entre les syndicats montréalais et le Bureau exécutif révèle que ce dernier jouissait d'une assez grande autorité.

\section{b) Services}

Les services offerts par l'Union internationale comprenaient une assurance-maladie, une assurance-vie et un fonds de grève. Un syndiqué en règle avec son syndicat depuis six mois était éligible à recevoir une allocation de maladie de 3,00\$ par semaine, somme qui fut augmentée à 5,00\$ pendant un maximum de treize semai-

\footnotetext{
97 Ibid., 48; Constitution of the Boot and Shoe Workers' Union, 1925, 27.

98 Constitution..., 1913, 40.

99 Ibid., 8.

100 A. E. Galster, op. cit., 83; The Shoe Workers'Journal, septembre 1903, 10-12.

101 A. E. Galster, op. cit., 86.

102 Ibid., 96-97.
} 
nes ${ }^{103}$. Toutefois, plusieurs restrictions limitaient ce droit: aucune prestation n'était versée pendant la première semaine de maladie: les bénéficiaires de plus de 60 ans lors de leur initiation ne recevaient que la moitié de la somme; et les femmes en couche n'y avaient pas droit. Il est intéressant de noter que, pour éviter les abus, trois syndiqués devaient faire une enquête séparée sur l'état du malade et que le bénéficiaire risquait de se voir couper les fonds s'il était surpris à l'extérieur de chez lui après huit heures du soir ${ }^{104}$.

La prudence de la fédération s'explique, car cette assurance représentait de loin son plus important poste à la colonne des dépenses. Selon les rapports annuels soumis au Ministère du Travail par l'Union internationale, elle aurait versé à ce poste un montant considérable à ses membres canadiens: 678 254,00 \$ entre 1912 et $1934^{105}$. En plus de se faire le défenseur des travailleurs dans l'entreprise, le syndicat jouait aussi le rôle d'une compagnie d'assurance. Au plus fort de la crise économique de 1929, l'Union internationale eut peine à rencontrer ses obligations au chapitre de l'assurance-maladie puisque ses effectifs diminuèrent considérablement. Elle organisa alors un référendum parmi les travailleurs pour supprimer le paiement de bénéfices-maladie et pour élever la prestation de $100,00 \$$ à $300,00 \$$ en cas de mortalité 106 . Ce changement permit de sortir la fédération d'une pénible situation financière, quoiqu'il rendait l'adhésion à la fédération moins avantageuse.

Depuis sa fondation, l'Union internationale versait aussi une prestation de $100,00 \$$ à un travailleur devenu invalide et un montant de $50,00 \$$ à $100,00 \$$ à sa famille à son décès ${ }^{107}$. Cette dernière somme fut augmentée à $100,00 \$$ et $300,00 \$$ selon la période d'adhésion au syndicat ${ }^{108}$. Pour les années où ce renseignement a été fourni au Ministère du Travail (1912 à 1934), $247925,00 \$$ furent versés à des travailleurs canadiens à ce chapitre ${ }^{109}$.

En outre, la fédération a généreusement puisé dans son fonds de grève pour soutenir les travailleurs montréalais. Elle a contribué financièrement à presque toutes les grèves (17) auxquelles ses

${ }_{103}$ Constitution..., 1913, 34; 1925, 40-41.

104 Constitution ..., 1925, 40-41.

105 Canada, Ministère du Travail, L'Organisation ouvrière au Canada, 1912-1932. Les données pour 1928 et 1930 manquent.

${ }_{106}$ Le Monde Ouvrier, 8 octobre 1932, 2.

107 The Shoe Workers' Journal, août 1900, 13.

108 Constitution..., 1925, 43.

109 Canada, Ministère du Travail, L'Organisation ouvrière au Canada, 1912-1934. Les données pour 1928 et 1930 manquent. 
syndicats ont été mêlés au Québec entre 1901 et 1925. Les trois grèves déclenchées à Montréal entre 1901 et 1906 lui avaient coûté $1702,14 \$$, somme à laquelle il faut ajouter un montant presque identique (1 721,30 \$) fourni au syndicat des travailleurs de Contrecoeur en $1901^{110}$. Ce syndicat, peu après sa fondation, avait réclamé l'allocation de 5,00\$ par semaine pour chaque gréviste sans avoir prévenu l'exécutif du déclenchement de la grève. Le président aurait pu lui refuser son aide, mais comme c'était le moment où l'Union internationale cherchait à s'implanter à Montréal, il en autorisa le versement aux grévistes ${ }^{111}$. Le geste s'avéra coûteux puisque le syndicat disparaissait quelque temps plus tard. Plusieurs grèves en 1920 et 1921 ont occasionné de fortes dépenses pour l'Union internationale puisqu'elles impliquaient des centaines de travailleurs qui avaient droit à 5,00 \$ par semaine, de la deuxième semaine de la grève jusqu'à ce que la grève fut gagnée ou déclarée terminée ${ }^{112}$. Dans le contexte montréalais, l'allocation de grève était généreuse puisqu'elle représentait la moitié du salaire d'un tailleur avant la guerre et le tiers environ dans les années vingt et trente. Il n'y a pas de doute que, dans l'esprit des travailleurs, ce fonds de grève constituait un atout précieux.

L'Union internationale a versé aux syndicats montréalais des sommes additionnelles lorsque sont survenues des difficultés particulières. Lors de la lutte contre la Fédération canadienne des cordonniers, elle a fourni $200,00 \$$ en assistance ${ }^{113}$; Tobin justifiait ce versement en disant: "we cannot afford to retire from that field, but, on the contrary, must bend every energy to overcome all obstacles...» ${ }^{114}$ Lorsque se produisaient des conflits importants, le Bureau exécutif donnait certaines sommes en plus de l'allocation de grève. Pendant le conflit de 1905 , l'exécutif vota 700,00 \$ pour aider ses «locaux» montréalais; en 1920, c'était $1000,00 \$$ qu'il leur attribuait pour les aider à vaincre la résistance du patronat. Utilisés pour des fins d'organisation ou de propagande, ces fonds représentaient des sommes importantes pour l'époque. Songeons que $1000,00 \$$ correspondaient à la cotisation annuelle de 115 membres versée au Bureau exécutif.

Bien sûr, les travailleurs québécois payaient en contre-partie une cotisation, dont les deux tiers prenaient le chemin de Boston.

110 The Shoe Workers' Journal, juillet 1909, 59.

111 Lettre de N.M. Eaton à C.L. Baine, 7 septembre 1901, Archives de la BSWU, General Executive Board, Actions and Decisions.

112 Constitution..., 1925, 50.

113 Lettre de J. Tobin à l'exécutif, 16 janvier 1902, 6 novembre 1902, Archives de la BSWU, General Executive Board, Actions and Decisions.

114 Ibid., 6 novembre 1902. 
Sur ces sommes acheminées aux États-Unis, nous ne possédons de données que pour certaines années financières ${ }^{115}$ :

TABLEAU III

REVENUS DE L'UNION INTERNATIONALE EN PROVENANCE DU QUÉBEC ET DU CANADA

\begin{tabular}{lcc} 
ANNÉE(S) & QUÉBEC & CANADA \\
\hline 1910 & $7057,47 \$$ & $11574,49 \$$ \\
1911 & 8410,33 & 13228,16 \\
$1920-21$ & 14058,90 & 22633,49 \\
$1924-25$ & 6803,17 & 12163,69 \\
$1928-29$ & 10051,13 & 14607,55 \\
\hline
\end{tabular}

Les rentrées variaient évidemment selon les effectifs de l'Union internationale au Québec et au Canada. Ces sommes ne constituaient qu'une faible portion des revenus totaux de l'Union internationale: 2 à $3 \%$ pour chacune des années ci-dessus (Québec).

Il aurait été intéressant de comparer les revenus et les dépenses effectuées par l'Union internationale au Québec. Mais nos données sont trop partielles pour qu'il soit possible de le faire. Au total, il est probable que les sorties d'argent vers les États-Unis furent supérieures aux rentrées, même en allouant à l'administration une somme proportionnelle aux effectifs québécois. Mais aux yeux des syndiqués québécois, cet inconvénient ne faisait pas le poids comparé aux nombreux avantages que leur valait l'affiliation internationale.

Aurait-il été possible pour ces syndiqués de créer une fédération canadienne d'ouvriers de la chaussure offrant les mêmes garanties de solidité et d'efficacité? Peut-être, mais à la condition qu'aux 1 500-2 000 ouvriers de l'Union internationale au Canada, on ajoute les 3 à 4000 membres de la Fédération catholique nationale des travailleurs en chaussures. Au total, une telle fédération aurait pu compter sur des effectifs de 5 à 7000 membres, alors que l'Union internationale possédait au Canada et aux États-Unis de 30 à 50000 membres entre 1910 et 1940 . Pour être viable, il aurait été préférable qu'une fédération canadienne eut moins d'autonomie et s'associât à d'autres fédérations professionnelles. C'était ce type de structure plus centralisée que la CTCC s'était donnée. C'est le drame du syndicalisme canadien que de s'être divisé très tôt par métier sous l'influence du syndicalisme international. Il n'aurait été possible de bâtir des syndicats canadiens via- 
bles qu'en regroupant les syndiqués dans des fédérations plus vastes.

\section{c) Le CMTC}

L'Union internationale a aussi entretenu des relations avec le Congrès des métiers et du travail du Canada (CMTC), centrale canadienne qui avait pour mission de jouer un rôle politique non partisan, soit celui d'influencer le législateur canadien. Au tournant du siècle, le CMTC a manifesté des velléités de jouer au Canada un rôle similaire à celui de la FAT aux États-Unis. Ralph Smith, son président de 1898 à 1901, ambitionnait de faire du CMTC une centrale dynamique orientée vers la promotion de syndicats nationaux ${ }^{116}$. Samuel Gompers, président de la FAT, et John Tobin, à cause de la lutte que la Fédération canadienne des cordonniers livrait à sa fédération à Montréal, étaient bien conscients du danger de telles idées susceptibles de conduire à la formation de syndicats parallèles aux leurs («dual unionism»). C'est pourquoi, en 1902, ils se sont unis et ont tout mis en oeuvre pour que le CMTC se dotât d'une nouvelle constitution qui lui interdirait l'affiliation de syndicats ayant juridiction concurrente avec une fédération internationale ${ }^{117}$.

Comme Gompers, Tobin partageait l'idée que le CMTC jouait au Canada un rôle semblable à une fédération du travail comme il en existait dans la plupart des États américains (State Federation of Labor). Il le déclarait clairement à une réunion du Bureau exécutif en juin 1907:

The CTLC does not bear the same relationship to our unions as the AFofL because the AFL is made up of international bodies, while the TLC is composed of affiliated local unions of international bodies, and bore the same relation as any State Branch in the United States. ${ }^{118}$

Le Bureau exécutif discutait alors de la demande du CMTC pour que l'Union internationale affilie directement ses syndicats canadiens au CMTC ${ }^{119}$. Après le congrès de Berlin (1902), les dirigeants du CMTC, pour renforcer leur organisation, se sont employés à convaincre les exécutifs de fédérations internationales d'affilier en bloc leurs syndicats canadiens et de payer directement le per capita pour leurs membres canadiens (18 sous par année en 1907). Cette

\footnotetext{
116 J. Rouillard, op. cit., 29.

117 Ibid., 74-78.

118 Procès-verbal du Bureau exécutif, 17 juin 1907, Archives de la BSWU, Report of Proceedings of General Executive Board.

119 Lettre de A. Verville et P. Draper aux exécutifs des fédérations internationales, 1er juin 1907, Archives de la BSWU, General Executive Board, Actions and Decisions.
} 
méthode rendait la tâche plus facile au CMTC puisqu'elle lui épargnait le travail de solliciter individuellement chaque syndicat international au Canada. Bon nombre de fédérations internationales se sont pliées à la requête du CMTC; l'Union internationale des travailleurs en chaussures a finalement accepté cette demande en $1918^{120}$.

L'Union internationale ne s'est cependant pas désintéressée des activités du CMTC puisque elle a défrayé à plusieurs reprises le coût du voyage et les frais de séjour de quelques-uns de ses membres aux congrès du CMTC. Les montants versés sont assez substantiels pour l'époque: par exemple, $150,00 \$$ en 1902 et 1903 , et $1125,00 \$$ en $1918^{121}$. Il est intéressant de relever que c'est dans les moments où le syndicalisme international était pris à partie au Canada que l'Union internationale a délié le plus généreusement les cordons de sa bourse. En 1902 et 1903, c'était pour bien s'assurer que la Fédération canadienne des cordonniers serait exclue du CMTC. La menace provenait en 1918 de l'Ouest canadien, dont les délégués cherchaient à orienter le congrès vers l'organisation des travailleurs sur la base de l'entreprise plutôt que sur celle du métier ${ }^{122}$. Les délégués internationaux, majoritaires au congrès de Québec en 1918, rejetèrent une proposition dans ce sens, ce qui entraîna le départ de l'aile radicale et la formation de la One Big Union quelques mois plus tard.

Cette nouvelle organisation constituait un grave danger pour le syndicalisme international au Canada. En août 1919, le secrétaire du CMTC, P.M. Draper, invitait les exécutifs des fédérations internationales à être bien représentés au prochain congrès de manière à faire échec à la tendance $O B U$ à l'intérieur du CMTC ${ }^{123}$. Un peu plus tard, il conseillait à l'Union internationale de nommer un organisateur pour éviter que la $O B U$ ne se répande dans la région torontoise ${ }^{124}$. Dans les deux cas, l'Union internationale a répondu favorablement à l'appel de Draper qui outrepassait son rôle en se faisant le protecteur du syndicalisme international au Canada.

\footnotetext{
${ }^{120}$ Procès-verbal du Bureau exécutif, 17 juin 1907 et 23 janvier 1918, Archives de la BSWU, Report of the Proceedings of General Executive Board.

${ }^{121}$ Lettres de J. Tobin au Bureau exécutif, 28 juillet 1902 et 24 août 1903, Archives de la BSWU, Report of the Proceedings of General Executive Board.

${ }_{122}$ Charles Lipton, The Trade Union Movement of Canada, 1827-1959 (Montréal, Canadian Social Publications, 1966), 281-282.

123 Procès-verbal du Bureau exécutif, 18 août 1919, Archives de la BSWU, Report of the Proceedings of General Executive Board.

${ }^{124}$ Lettre de P. Draper à l'Union iniernationale, Archives de la BSWU, Procès-verbal du Bureau exécutif, 22 novembre 1920, Archives de la BSWU, Report of the Proceedings of General Executive Board.
} 
Les ressources financières de l'Union internationale ont donc servi non seulement à protéger les travailleurs canadiens contre le patronat, mais aussi à assurer la défense du syndicalisme international au Canada. Il est fort probable que les autres fédérations ont manifesté le même souci de garder le contrôle du CMTC en s'assurant d'être représentées par le maximum de délégués. Comme il était onéreux de faire voyager des délégués à travers le Canada, beaucoup de syndicats nationaux ne se prévalaient pas de leur droit d'être représentés parce qu'ils ne disposaient pas de fonds suffisants. Leur faiblesse permettait aux «internationaux» de garder en définitive la haute main sur la centrale canadienne.

\section{Conclusion}

L'Union internationale eut beaucoup plus de difficultés à s'implanter au Québec qu'en Ontario. Deux facteurs ont particulièrement entravé son expansion: le nationalisme et l'opposition du clergé catholique. À cause de son origine «étatsunienne», l'Union internationale invitait à des réactions nationalistes. L'organisation rivale à Montréal au début du siècle, la Fédération canadienne des cordonniers, misait essentiellement sur le nationalisme pour se développer; ses dirigeants ne comprenaient pas pourquoi il fallait s'en remettre à une organisation étrangère pour défendre les intérêts des travailleurs canadiens.

L'action du clergé a également représenté un obstacle majeur au développement de l'Union internationale qui fut forcée à toutes fins utiles de se cantonner dans la région montréalaise. Le caractère pluraliste de la métropole, au niveau ethnique et religieux, affaiblissait le poids des opinions du clergé, même auprès des francophones. Montréal avait une dimension nord-américaine qui en atténuait les traits français et catholique. Le facteur religieux qui empêcha l'Union internationale de s'implanter à Québec, s'est avéré encore plus désastreux pour elle après la guerre. Le clergé transforma les syndicats indépendants de Québec en syndicats confessionnels alors que l'industrie de la chaussure se déplaçait vers les centres ruraux où son influence était déterminante. L'expansion du syndicalisme catholique en province permit de réunir un bassin de travailleurs de la chaussure suffisant pour conférer aux syndicats catholiques une viabilité et une solidité qui avaient fait défaut à la Fédération canadienne. Cette évolution rendait les travailleurs moins sensibles à l'argument invoqué par l'Union internationale, à savoir qu'elle était la seule organisation qui possédait les ressources suffisantes pour faire fléchir le patronat.

Lors de l'implantation de l'Union internationale à Montréal, la force que lui conférait son envergure nord-américaine a été un 
atout précieux pour gagner l'adhésion des travailleurs. Entre l'appel au sentiment national que lançait la Fédération canadienne et les garanties de solidité et d'efficacité qu'offrait l'Union internationale, les travailleurs montréalais ont finalement choisi la seconde alternative. «Les motifs qui nous poussent à nous solidariser, disait l'agent d'affaires de l'Union internationale, Alphétus Mathieu, n'ont rien à faire avec la question de patriotisme... Pour nous, l'union des ouvriers est une question purement d'affaires.» ${ }^{125}$ En plus de raffermir le pouvoir de négociation des travailleurs, la cotisation à l'Union internationale leur valait des prestations de grève, une assurance-maladie et une assurance-vie. Ces assurances avaient aussi l'avantage pour l'Union internationale de retenir les travailleurs au sein du syndicat, car, en le quittant, ils perdaient tous les bénéfices accumulés.

À ces éléments qui militaient en faveur de l'adhésion internationale, il faut ajouter l'appui de certains manufacturiers dont l'Union internationale avait acquis la sympathie en leur faisant miroiter des ventes plus faciles grâce à la marque syndicale internationale. Une large part de ses syndiqués ont été recrutés par l'intermédiaire du patronat. La fragilité de ce mode de recrutement ressortit clairement après la guerre avec la perte graduelle d'intérêt des manufacturiers pour la marque syndicale internationale.

Cette méthode qui avait été un atout certain au début du siècle ne suffisait plus pour assurer la progression de l'Union internationale. Aussi, c'est à une quasi-stagnation à laquelle elle fut acculée au Québec de 1920 à 1940; les syndicats vivaient sur leur acquis d'avant-guerre. Les forces qui militaient contre la présence internationale au Québec, le nationalisme, le clergé et le syndicalisme catholique, l'emportaient sur les éléments qui avaient constitué des avantages déterminants au début du siècle, l'appui des employeurs et le lien international. 